\title{
Age Prediction through Pelvis X-Ray Images A Case Based approach to Problem Solving
}

\author{
Diana Martins \\ Departamento de Informática \\ Universidade do Minho \\ Braga, Portugal \\ dscm_diana@hotmail.com
}

Victor Alves

Centro Algoritmi

Universidade do Minho

Braga, Portugal

valves@ di.uminho.pt

\author{
Henrique Vicente \\ Departamento de Química, Escola de Ciências e \\ Tecnologia, Universidade de Évora, Évora, Portugal \\ Centro Algoritmi, Universidade do Minho, Braga, Portugal \\ hvicente@uevora.pt \\ José Neves* \\ Centro Algoritmi, Universidade do Minho \\ Braga, Portugal \\ jneves@di.uminho.pt \\ * Corresponding author: phone: +351-934201337; fax: \\ +351-253604471; e-mail: jneves@di.uminho.pt
}

\begin{abstract}
It is well known that the dimensions of the pelvic bones depend on the gender and vary with the age of the individual. Indeed, and as a matter of fact, this work will focus on the development of an intelligent decision support system to predict individual's age based on pelvis' dimensions criteria. On the one hand, some basic image processing technics were applied in order to extract the relevant features from pelvic X-rays. On the other hand, the computational framework presented here was built on top of a Logic Programming approach to knowledge representation and reasoning, that caters for the handling of incomplete, unknown, or even self-contradictory information, complemented with a Case Base approach to computing.
\end{abstract}

Keywords-Intelligent Systems; Pelvis X-ray Images; Logic Programming; Case Based Computing. 